\title{
Article \\ Spectrum of Disease Manifestations in Patients with Selective Immunoglobulin E Deficiency
}

\author{
César Picado ${ }^{1,2,3, *}$, Iñaki Ortiz de Landazuri ${ }^{4}\left(\mathbb{C}\right.$, Alexandru Vlagea ${ }^{4}$, Irina Bobolea ${ }^{1,2,3}$, Ebymar Arismendi ${ }^{1,2,3} \mathbb{C}^{\circ}$, \\ Rosanel Amaro 1,2,3, Jacobo Sellarés ${ }^{1,2,3}{ }^{\mathbb{C}}$, Joan Bartra ${ }^{1,2}$, Raimon Sanmarti ${ }^{2,5}$, José Hernandez-Rodriguez ${ }^{2,6} \mathbb{C D}$, \\ José-Manuel Mascaró $^{2,7}{ }^{\circledR}$, Jordi Colmenero ${ }^{2,8,9}$, Eva C. Vaquero ${ }^{2,9,10}$ and Mariona Pascal ${ }^{2,4}$
}

Citation: Picado, C.; Ortiz de Landazuri, I.; Vlagea, A.; Bobolea, I.; Arismendi, E.; Amaro, R.; Sellarés, J.; Bartra, J.; Sanmarti, R.;

Hernandez-Rodriguez, J.; et al. Spectrum of Disease Manifestations in Patients with Selective Immunoglobulin E Deficiency. J. Clin. Med. 2021, 10, 4160. https:// doi.org/10.3390/jcm10184160

Academic Editors: Rita Consolini and Giorgio Costagliola

Received: 20 August 2021

Accepted: 12 September 2021

Published: 15 September 2021

Publisher's Note: MDPI stays neutral with regard to jurisdictional claims in published maps and institutional affiliations.

Copyright: (c) 2021 by the authors. Licensee MDPI, Basel, Switzerland. This article is an open access article distributed under the terms and conditions of the Creative Commons Attribution (CC BY) license (https:// creativecommons.org/licenses/by/ $4.0 /)$.
1 Institut Clinic Respiratory, Hospital Clinic, Universitat de Barcelona, 08036 Barcelona, Spain; Bobolea@clinic.cat (I.B.); earismen@clinic.cat (E.A.); ramaro@clinic.cat (R.A.); sellares@clinic.cat (J.S.); JBARTRA@clinic.cat (J.B.)

2 Institut d'Investigacions Biomèdiques August Pi i Sunyer (IDIBAPS), 08036 Barcelona, Spain; sanmarti@clinic.cat (R.S.); jhernan@clinic.cat (J.H.-R.); mascaro@clinic.cat (J.-M.M.); jcolme@clinic.cat (J.C.); evaquero@clinic.cat (E.C.V.); MPASCAL@clinic.cat (M.P.)

3 Centro de Investigaciones Biomédicas en Red de Enfermedades Respiratorias (CIBERES), 28029 Madrid, Spain

4 Immunology Department, CDB. Hospital Clinic, Universitat de Barcelona, 08036 Barcelona, Spain; ortizdelan@clinic.cat (I.O.d.L.); vlagea@clinic.cat (A.V.)

5 Department of Rheumatology, Hospital Clinic, Universitat de Barcelona, 08036 Barcelona, Spain

6 Department of Autoimmune Diseases, Hospital Clinic, Universitat de Barcelona, 08036 Barcelona, Spain

7 Department of Dermatology, Hospital Clinic, Universitat de Barcelona, 08036 Barcelona, Spain

8 Liver Unit, Hospital Clinic, Universitat de Barcelona, 08036 Barcelona, Spain

9 Centro de Investigaciones en Red de Enfermedades Hepáticas y Digestivas (CIBEREHD), 28029 Madrid, Spain

10 Department of Gastroenterology, Hospital Clinic, Universitat de Barcelona, 08036 Barcelona, Spain

* Correspondence: cpicado@ub.edu

Abstract: Background: Selective IgE deficiency (SIgED) has been previously evaluated in selected patients from allergy units. This study investigates the effects of SIgED on the entire population in a hospital setting and sought to delineate in detail the clinical aspects of SIgED. Methods: A retrospective study of the data obtained from electronic medical records of 52 adult patients ( $56 \%$ female) with a mean age of 43 years and $\mathrm{IgE}$ levels of $<2.0 \mathrm{kU} / \mathrm{L}$ with normal immunoglobulin (Ig) IgG, IgA, and IgM levels, seen at our hospital, without selection bias, from 2010 to 2019. Results: Recurrent upper respiratory infections were recorded in 18 (34.6\%) patients, pneumonia was recorded in $16(30.7 \%)$ patients, bronchiectasis was recorded in 16 (30.7\%) patients, and asthma was recorded in $10(19.2 \%)$ patients. Eighteen patients (34.6\%) suffered autoimmune clinical manifestations either isolated (19\%) or combining two or more diseases (15\%), Hashimoto's thyroiditis being the most frequent (19\%), which was followed by arthritis (10\%) and thrombocytopenia and/or neutropenia (5.7\%). Other less frequent associations were Graves' disease, primary sclerosing cholangitis, Sjögren's syndrome, and autoimmune hepatitis. Eczematous dermatitis (15.3\%), chronic spontaneous urticaria (17.3\%), and symptoms of enteropathy (21\%) were also highly prevalent. Thirty percent of patients developed malignancies, with non-Hodgkin lymphomas (13.4\%) being the most prevalent. Conclusions: The clinical manifestations of SIgED encompass a variety of infectious, non-infectious complications, and malignancy. Since it cannot be ruled out that some type of selection bias occurred in the routine assessment of IgE serum Ievels, prospective studies are required to better characterize SIgED and to determine whether it should be added to the list of antibody deficiencies.

Keywords: autoimmune diseases; Immunoglobulin E; Immunoglobulin deficiency; infections; malignancy 


\section{Introduction}

A recently updated classification distributes innate errors of immunity into 10 groups, one of which is considered to be due to "antibody deficiencies" (Group 3) [1,2].

Immunoglobulins A (IgA), M (IgM), and G (IgG) are central in the humoral immune response and play a fundamental role in protecting against infections caused by all kinds of agents (viruses, bacteria, protozoa, parasites), and they represent the defense mediated by antibodies, which are part of the so-called acquired immunity [3].

Immunoglobulin E (IgE) has been conventionally related to the immune response against helminth infection, and its levels are particularly high in patients who suffer from a parasitic infestation [4]. IgE is also involved in type I hypersensitivity allergic reactions, which are diseases where it is also common to find high levels of specific IgE against allergens. Most IgE is found bound to its high-affinity receptor $F_{c} \in R I$ located on the surface of mast cells and basophils. The binding of the allergen to the specific IgE/Fc $\in$ RI complex triggers the degranulation of mast cells and basophils that release numerous substances (vasoactive, bronchoconstrictors, interleukins), which are ultimately responsible for the clinical manifestations of the allergic response (rhinitis, asthma, urticaria, angioedema, anaphylaxis) [5].

Various types of immunodeficiencies associated with low levels of one or a combination of IgA, IgG, and IgM immunoglobulins are recognized. [1,2]. The most studied combined form is known as "common variable immunodeficiency" (CVID), which is a disorder characterized by reduced serum levels of IgG, which can be combined with a reduction of IgA or IgM, or both, which is associated with recurrent sinopulmonary infections, autoimmune disorders, granulomatous diseases, and increased risk of malignancy and altered response of antibodies against infections $[6,7]$.

Selective IgG deficiency (SIgGD) encompasses any subject with a serum IgG level below normal range with normal IgA and IgM levels. Studies comparing the SigGD and CVID patients found that the CVID group was more likely to have bronchiectasis, poorer responses to vaccines, and a higher incidence of autoimmune cytopenias, granulomas, splenomegaly, and lymphoid neoplasms than those with SigGD [8].

IgG subclass deficiency (IgGSD) is a heterogeneous subtype of primary immunodeficiency, which is defined as the triad of frequent or severe respiratory tract infections, subnormal levels of one or more of the four IgG subclasses, and decreased IgG response to pneumococcal polysaccharides. Many adults with IgGSD also have autoimmune conditions or atopy $[9,10]$.

Selective IgA deficiency (SIgAD) [11,12], and selective IgM (SIgMD) $[13,14]$ are diagnosed in a diverse group of patients, ranging from completely asymptomatic individuals to people with recurrent infections, allergic diseases, autoimmune processes, and malignant tumors.

The question is: are there any similar diseases associated with selective $\operatorname{IgE}$ deficiency (SIgED)? Conventionally, normal serum IgE values are considered to range between the technical detection limit $(\leq 2 \mathrm{kU} / \mathrm{L})$ and up to $100 \mathrm{kU} / \mathrm{L}$. An excess of $\operatorname{IgE}(>100 \mathrm{kU} / \mathrm{L})$ can be established but, in contrast to the other immunoglobulins, there is no generally accepted minimum level to establish an IgE deficiency. In various studies in the literature, different cut-off points have been used to define IgE deficiency [15-19]. Most clinicians do not attribute any pathological significance to very low $\operatorname{IgE}$ values, even those that are unquantifiable ( $\leq 2 \mathrm{kU} / \mathrm{L})$, which are usually considered as "normal".

Low $\operatorname{IgE}$ is frequently associated with deficiencies in other immunoglobulins, particularly in patients with CVID [20-22]. Based on this observation, the use of routine IgE measurement has been proposed as the first step to detect the presence of CVID [21,22].

In the classification of primary immunodeficiencies attributed to antibody deficiency, the presence of low $\operatorname{IgE}$ values is mentioned, but it is always associated with deficiencies in some of the other immunoglobulins [1,2]. The possibility of an immunodeficiency associated only with an SIgED is not considered in the classification. However, a few 
studies have reported that an SIgED may be the biomarker of an immunodeficiency with a significant clinical impact that has been overlooked until now [23-26].

The studies analyzing the potential role of SIgED are retrospective and include a limited number of cases. Furthermore, most of the patients included in these studies were selected from allergy units $[23,26]$ or were patients having any allergy-related symptoms and/or requesting antiallergy medications [25], which is a bias that could have limited the spectrum of diseases found associated with SIgED. Despite these limitations, it is worth noting that these studies show that individuals with a low level of IgE, with normal values for the other immunoglobulins, present recurrent respiratory infections, suffer from autoimmune diseases, and upper and lower airway diseases [23-26], similar to those described in patients with CVID [6-8], IgGSD [9] or with SIgGD [8], SIgAD [11,12], and SIgM D $[13,14]$.

The predisposition to develop neoplasms in patients with antibody deficiency, either in combination or due to selective deficits of IgA or IgM, is widely documented [27]. In the same way, the scientific information supports that IgE deficiency is a predisposing factor for the development of malignancies [28].

The hypothesis of this study establishes that isolated IgE deficiency is associated with diseases similar to that described in other antibody deficiencies, but its clinical spectrum has been underestimated.

This study is the first to research the effects of SIgED in the entire population in a hospital setting with a 2-year follow up and sought to delineate in detail the clinical aspects of SIgED.

\section{Patients and Methods}

Any patient who was found to have an IgE concentration $\leq 2 \mathrm{kU} / \mathrm{L}$ with normal IgG, $\operatorname{IgM}$, and IgA concentrations with at least 2-year follow up at our institution between January 2010 and December 2019 was included in the study. A total of 151 patients were analyzed, of whom 99 were excluded for different reasons shown in Figure 1. The remaining 52 patients with SIgED and regular follow-up in the hospital were included in the study. Medical records were reviewed and discussed together with the various specialists involved in their routine care. Of the 52 patients, 31 were female $(56 \%)$, and the mean age was 43 years (range 18-87).

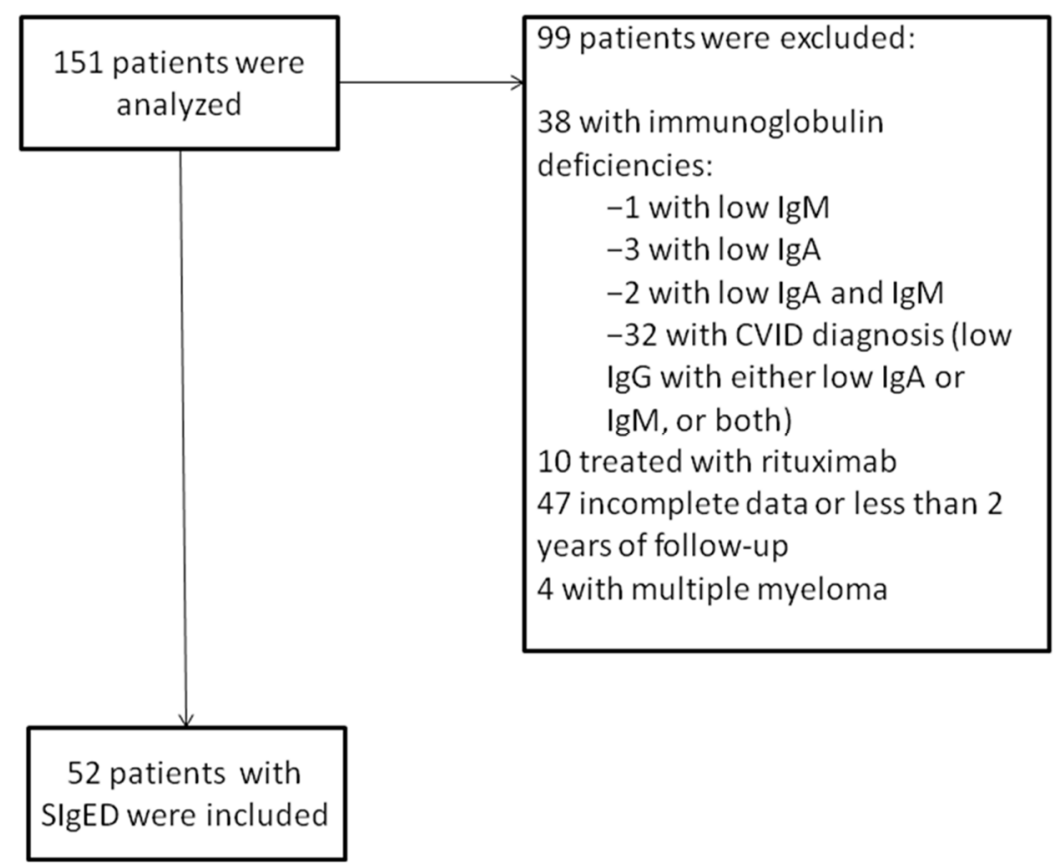

Figure 1. Flow chart of patients analyzed. 
In patients with a suspicion of either a respiratory or food allergy, we routinely perform skin prick tests (SPTs) in our institution with a panel of commercial allergenic extracts of the most prevalent aeroallergens and food allergens in our area (Laboratorios LETI, Madrid, Spain). Foods suspected by the clinical history and not included in the standard panel are also usually tested with a commercial extract if available, or by prick-prick according to standard methods. Serum levels of IgG, IgA, IgM, and IgGs were measured by immunoturbidimetry (Atellica NEPH 630 Solution System. Siemens Healthineers, Germany). Serum total and specific IgE levels were measured by immunofluorescence enzyme immunoassay (ImmunoCAP, ThermoFisherScientific, Uppsala, Sweden). Serum IgA, IgM, and IgG values of the participants were: IgM 1.10 (range, $0.41-2.42) \mathrm{g} / \mathrm{L}$ (normal values $(0.36-2.6 \mathrm{~g} / \mathrm{L}$ ); $\mathrm{IgG}$ $10.7 \mathrm{~g} / \mathrm{L}$ (range, 7.10-13.30) g/L; and IgA $2.12 \mathrm{~g} / \mathrm{L}$ (range 0.95-4.80) g/L (normal values 0.66-3.6 g/L). The study was approved by the Ethics Committee of the Hospital Clinic (Ethical Code: HCB/2021/0758).

\section{Results}

\subsection{Infections}

Three or more yearly upper respiratory infections (URI) (rhinorrhea, nasal congestion, and productive cough), requiring antibiotic therapy for at least two consecutive years, were recorded in $18(34.6 \%)$ of the SIgED patients. Sixteen patients $(30.7 \%)$ had suffered one or more episodes of pneumonia (range 1 to 3). Median IgG, IgM, and IgA levels were not significantly different in patients with or without URI or pneumonia (data not shown). In two patients, chronic respiratory infection with $M$. avium complex was identified. Recurrent episodes of otitis were recorded in four patients. Three patients had suffered from herpesvirus infections, and one had suffered from chronic pyelonephritis.

\subsection{Lung Diseases}

Twenty-nine patients underwent chest computed tomography (CT) scanning. The radiological study demonstrated the presence of bronchiectasis in 16 patients (30.7\% of total sample) affecting between one and three lobes and mostly cylindrical, peribronchial thickening in three, air trapping in two, atelectasis in three, micronodules in three, cyst in three, pulmonary emphysema in three (all ex-smokers), ground glass opacities in six, and interstitial lung fibrosis in one. The chest CT scan was considered normal in six patients (all of them suffering from frequent respiratory infections). In two patients, the combination of chest CT findings (micronodules, cysts), bronchoalveolar lavage (BAL) fluid results (lymphocytic inflammation and multinucleated giant cell), and the lung biopsy of a nodule (lymphocytic infiltration) indicated the presence of lymphocytic interstitial lung disease. Ten (19.2\%) patients were diagnosed with asthma with different levels of severity. Eight patients (15.3\%), six of them associated with asthma, referred symptoms of allergic rhinitis, and four of them reported clinical symptoms apparently exacerbated seasonally (spring, autumn). In all patients, SPTs and specific IgE for common allergens) were negative (Table 1).

\subsection{Autoimmune Diseases}

Eighteen patients (34.6\%) suffered autoimmune clinical manifestations, either isolated $(19 \%)$ or combining two o more diseases $(15 \%)$. Hypothyroidism was diagnosed in 10 patients $(19.2 \%)$, eight secondary to Hashimoto's thyroiditis, and two resulted from previously treated hyperthyroidism (Graves' disease). Other less frequently found autoimmune diseases are shown in Table 1. 
Table 1. Non-infectious complications.

\begin{tabular}{|c|c|}
\hline & No. $(\%)$ \\
\hline \multicolumn{2}{|l|}{ Airway/Lung diseases } \\
\hline Bronchiectasis & $16(30.7)$ \\
\hline Asthma & $10(19.2)$ \\
\hline Rhinitis & $8(15.3)$ \\
\hline Lymphocytic interstitial lung disease * & $2(3.8)$ \\
\hline Interstitial lung fibrosis & $1(1.9)$ \\
\hline \multicolumn{2}{|l|}{ Autoimmune diseases } \\
\hline Hashimoto's disease & $8(15.4)$ \\
\hline Arthritis (1 RA, 4 undifferentiated) & $5(9.6)$ \\
\hline Thrombopenia ( 2 associated with neutropenia) & $4(7.7)$ \\
\hline Neutropenia & $3(5.8)$ \\
\hline Aphthous stomatitis & $3(5.8)$ \\
\hline Graves' disease & $2(3.8)$ \\
\hline Vitiligo & $2(3.8)$ \\
\hline SLE & $2(3.8)$ \\
\hline Alopecia & $1(1.9)$ \\
\hline Acute hepatitis & $1(1.9)$ \\
\hline Sjögren's syndrome & $1(1.9)$ \\
\hline \multicolumn{2}{|l|}{ Gastrointestinal and liver diseases } \\
\hline Symptoms of enteropathy ${ }^{* *}$ & $11(21)$ \\
\hline PSC & $2(3.8)$ \\
\hline Ulcerative colitis (associated to PSC) & $2(3.8)$ \\
\hline Cirrhosis (secondary to PSC) & $2(3.8)$ \\
\hline \multicolumn{2}{|l|}{ Other manifestations } \\
\hline Chronic spontaneous urticaria & $9(17.3)$ \\
\hline Eczematous dermatitis & $8(15.3)$ \\
\hline Polyarthralgia & $9(17.3)$ \\
\hline Fatigue & $7(13.4)$ \\
\hline Arterial hypertension & $13(33.3)$ \\
\hline
\end{tabular}

PSC, primary sclerosing cholangitis; RA, rheumatoid arthritis; SLE, systemic lupus erythematous. * Diagnosis based on CT scan images; Bronchoalveolar lavage lung fluid findings and biopsy of a lung nodule. ${ }^{* *}$ Chronic or intermittent diarrhea, abdominal pain and bloating.

\subsection{Gastrointestinal and Liver Diseases}

Symptoms of enteropathy such as intermittent or persistent chronic diarrhea, abdominal pain, and bloating were present in 11 patients (21\%). Some patients associated their symptoms with the ingestion of certain foods. In all cases, both allergen SPTs and specific IgE studies with the putative culprit foods were negative. Fructose and lactose intolerance were assessed in four patients, and only one tested positive in the lactose test. Celiac disease was excluded in most (nine patients) but not all patients by anti-transglutaminase IgG serology. A gluten-free diet was tested in four patients with inconsistent or negative symptomatic response. Biopsies of colon mucosa and/or small intestine were obtained in six patients, and the histological findings were: intraepithelial lymphocytosis (four patients), lymphoid hyperplasia forming aggregates (one patient), and enteritis with chronic inflammation, eosinophilic infiltration, crypt distortion, and gland destruction (one patient). Acute severe autoimmune hepatitis was diagnosed in one patient who had required two liver transplantations. Two patients suffered from primary sclerosing cholangitis (PSC) progressing to cirrhosis requiring liver transplantation. The two patients also suffered from ulcerative colitis (Table 1).

\subsection{Cutaneous Findings}

Eczematous dermatitis (eight patients, 15.3\%) associated with moderate or severe itching in most cases, chronic spontaneous urticaria (CSU) (nine patients, 17.3\%), angiedema (four patients associated with CSU), and chronic leg ulcers (two patients) were present among the SIgED patients (Table 1). 


\subsection{Tumours}

Sixteen $(30.7 \%)$ patients developed malignancies including non-Hodgkin lymphomas (seven patients, $13.4 \%$ ), chronic lymphocytic leukemia (two patients, one evolving from a lymphoma), and various types of malignant and non-malignant tumors, as shown in Table 2. Four patients developed more than one tumor.

Table 2. Lymphomas and other tumors.

\begin{tabular}{lc}
\hline & No. (\%) \\
\hline Lymphomas and Leukemias & 3 \\
Diffuse Large B cell lymphoma & 1 \\
Follicular cell lymphoma & 1 \\
Burkitt lymphoma & 1 \\
Lymphocytic Lymphoma/CLL & 1 \\
Lymphoma B cell, not otherwise specified & 1 \\
CLL & \\
Other & 3 \\
Melanoma & 2 \\
Breast & 2 \\
Skin cancer (basal cell carcinoma) & 1 \\
Cholangiocarcinoma & 1 \\
Hepatocarcinoma & 1 \\
Gynaecological (endometrial carcinoma) & 1 \\
Clear cell renal carcinoma & 1 \\
Meningioma & 1 \\
\hline Neurinoma &
\end{tabular}

\subsection{Other}

Mastocytosis (two patients), monoclonal gammopathy of undetermined significance (MGUS) (two patients), fatigue (seven patients, 13.4\%), and polyarthralgia (nine patients, $17.3 \%$ ) were also reported by some patients as major complaints. Follicular hyperplasia affecting lymph nodes located in the mediastinum, armpits, groin, supraclavicular area, or abdomen were found in eight (15.3\%) patients, which, when biopsied (three patients), showed a pattern of non-specific lymphoid reactivity, although one of them later evolved to a lymphoma. Arterial hypertension (13 patients, 33.3\%) and ischemic heart disease (four patients, 7.7) were also documented.

\subsection{SIgED and IgG Subclasses}

Serum levels of IgG1, IgG2, IgG3, and IgG4 had been assessed in 14 patients and were normal in all but three patients: one with low IgG3 and two with low IgG4 (data not shown).

\section{Discussion}

It is generally accepted that low levels of $\operatorname{Ig} \mathrm{A}, \operatorname{IgM}$, and $\operatorname{IgG}$ predispose to respiratory bacterial and viral infections. The high incidence of URI and pneumonia in our patients with SIgED is in keeping with that reported for CVID [8,9,29], SIgGD [8], IgGSD [9,10], SIgAD [11,12], and SIgMD [13,14]. The mechanism by which an SIgED may also predispose to lung infections remains to be elucidated. $\mathrm{IgE}$ is usually related to protection against parasites [4], but its role in other infections is not usually considered, despite there being studies that have demonstrated the presence of specific IgE antibodies against viruses such as H1N1 influenza [30], respiratory syncytial [31], HIV1 [32], varicella [33], parvovirusB19 [34], and rhinovirus (RV) [35]. Anti-HIV1 IgE has been shown to inhibit HIV1 production in infected cell culture, the inhibitory effect being reversed when IgE was removed from the culture [32]. In a study involving children with HIV-1 infection, 
opportunistic infections were less frequent in children with high serum IgE levels than in those with low IgE levels [36].

It is generally assumed that IgE does not play any relevant role in the immune response against bacteria. However, there are studies reporting that IgE antibodies provide immunity against bacteria such as Borrelia burgdorferi [37]. It was recently discovered that the antibacterial activity of mast cells against Staphylococcus aureus (SA) in mice was markedly enhanced by the presence of IgE directed against bacterial components. Animal models deficient in IgE or FceRI were unable to mount protective immune responses against SA infections [38]. Furthermore, other authors have found that SIgED deficiency predisposes to recurrent upper and lower airways with common respiratory bacteria such as Haemophilus influenza, Moraxella catarrhalis, and Streptococcus pneumoniae [23].

Taken together, these findings support the notion that a reduced synthesis of IgE may result in an immunodeficient response against virus and bacteria. As far as we know, the response to vaccines of patients with SIgED has never been studied.

Two of our patients (3.8\%) had chronic Mycobacterium avium infection. The patients had clinical and radiological findings suggestive of 'Lady Windermere Syndrome' (LWS), which is characterized by chronic bronchiectasis in slender women, with scoliosis and/or pectus excavatum, and chronic productive cough. Multigenic variants with potential defects in proteins encoded by various genes might contribute to LWS by reducing both IFN- $\gamma$ production and increasing transforming growth factor (TGF)- $\beta$ levels in response to nontuberculous mycobacterium (NTM) [39-42]. NTM infection has been reported in a very small percentage of patients with CVID (0-1\%) [43]. Chronic respiratory infection with $M$. avium complex and bronchiectasis were identified in $5 \%$ of patients with SIgAD [44]. So far, in patients with SIgAD, SIgGD, and IgGSD, no NTM infections have been reported. The potential role of SIgED in NTM infection is unknown and should be evaluated in a larger series of patients with lungs infected with these pathogens.

It is generally assumed that in CVID patients, recurrent airway infections and persistent airway inflammation can lead to a vicious circle airway remodeling process resulting in bronchiectasis [43]. A recent analysis of existing data on the clinical presentation of CVID found that bronchiectasis was present in the CT scan in almost one-third of patients (28\%, 95\% CI 18-40) [29]. Bronchiectasis has been found in up to $14 \%$ of SIgAD patients and is more commonly reported when associated with IgG subclass deficiency [44-46]. We found that bronchiectasis was present in $30.7 \%$ of our SIgED patients, which is a percentage similar to that reported in CVID, which is an observation that suggests that the lack of IgE has a significant negative impact on the immune defense mechanisms of the lung. In contrast to our findings, bronchiectasis is not even mentioned in the few studies reporting the clinical manifestations present in SIgED patients, which is most probably due to the lack of CT scan evaluation in patients with frequent respiratory infections [23-26].

Viral infections are a strong risk factor for developing asthma in children, and they are major contributors to exacerbations of asthma in both children and adults [47]. The link between viruses and upper (rhinitis) and lower respiratory diseases (asthma) might explain the high percentage of patients with CVID that are diagnosed with asthma $(25 \%, 95 \%$ CI $17-35)$ and rhinitis (18\%, 95\% CI 8-31) [29]. What is not yet clear is the mechanism underlying this association. Are CVID patients with asthma-like clinical symptoms a distinct hyperreactive airway phenotype? Or, are they subjects to genetic factors predisposing them to develop asthma, which is unmasked early by the presence of the immunodeficiency? Mutations in the TNFRSF13B gene have been found in CVID patients [48] and are also associated with an increased risk of asthma development [49].

CVID patients with asthma and rhinitis are often clinically characterized as allergic [29,43]. Interestingly, some of our patients reported nasal and bronchial allergiclike reactions-a few of the associated with seasonal exacerbations. This is not surprising, given the presence of ultralow serum levels of IgE, SPTs, and that the in vitro tests for serum-specific IgE against common allergens were negative in all patients. It is theoretically plausible that allergic-type symptoms could be due to the presence of $\operatorname{IgE}$ in the 
respiratory tract, which is something similar to so-called local allergic rhinitis (LAR) and local allergic asthma (LAA) [50,51]. These diseases are characterized by the negativity of the skin-prick test and serum-specific IgE for all relevant aeroallergens in a patient with upper and lower airway symptoms suggestive of allergy, and who tested positive in the nasal and bronchial allergen challenge [50,51]. Although the cells and the main sites of IgE production in humans remains to be fully characterized, it is assumed that IgE is produced in the peripheral blood and locally in various tissues, including the nose and lung [52]. One may speculate that airway mucosal IgE in patients with SIgED is still capable of developing respiratory allergic responses in a similar way to that described in LAR and LAA [51,52]. Interestingly, patients with CVID, IgE deficiency, and a history suggestive of allergic asthma with negative allergen SPTs did not show any bronchial reactions when subjected to an allergen challenge, but the exposure to allergens increased the airway response to histamine [53]. Whether the acquired airway hyperresponsiveness was due to a local IgE-dependent or another non-IgE related mechanism remains to be clarified. It is also unclear whether allergen-induced hyperresponsiveness can indirectly account for the symptoms of those IgE-deficient patients associated with allergen exposure. Allergy symptoms may have been confused with unspecific airway hyperreactivity-related clinical manifestations.

Similar to CVID, SIgAD has also been associated with allergic rhinoconjunctivitis and asthma $[44,54,55]$. However, the prevalence of these diseases shows large differences among studies, ranging from $13 \%$ [44] to $83 \%$ [55]. Furthermore, one age- and gendermatched survey found an increased prevalence of allergic rhinoconjunctivitis, but no differences were found in asthma prevalence between SIgAD and controls [55]. Thirty five percent of patients with SIgMD had atopic diseases, including allergic rhinitis and asthma [45], while allergic asthma and/or allergic rhinitis were the second commonest manifestations in patients with IgGSD without any subclass predominance [56].

In previous studies, SIgED has been found to be associated with a higher prevalence of non-allergic reactive airways disease (rhinorrhea, nasal congestion, dry cough, and/or wheezing) (73\%) compared with controls (20\%) [23], and with asthma or hyperreactive airway disease ( $26.5 \%$ vs. controls $6.8 \%)$ in children but not in adults [25]. The prevalence of asthma (19.2\%) found in our study was higher than that reported in the adult Spanish population (range 10-16.7\%) [57].

Interstitial lung disease (ILD) is a frequent (15-60\%) non-infectious complication of CVID [58]. The histology of ILD in CVID shows heterogeneous and often mixed patterns, including lymphoid hyperplasia, lymphoid interstitial pneumonitis, follicular bronchiolitis, non-necrotizing granulomatous inflammation, organizing pneumonia, and interstitial fibrosis [59]. Granulomatous-lymphocytic interstitial lung disease (GLILD) is often used as a term to describe ILD with lymphocytic infiltrates and/or granulomata in CVID [59]. However, not all ILD in CVID have pulmonary granulomata, and therefore, the term does not fully cover the heterogeneous spectrum of the histopathology found in lung samples from CVID patients [59]. Approximately $20 \%$ of patients with ILD present polyclonal lymphocytic infiltration or non-malignant hyperplasia of the lymph nodes in addition to granuloma [60]. Monogenic disorders causing CVID-like diseases have also been reported in patients with ILD [61-63]. Patients with ILD have distinct clinical and immunological phenotypes in keeping with immune dysregulation, in contrast to those without ILD or those with bronchiectasis alone [64]. Recent studies have shown that ILD is also present in the lung of patients with selective immunoglobulin deficiencies, including SIgAD, SIgGD, and IgGSD, with a pattern of lymphoid proliferation and granulomata identical to that found in CVID [65-67]. Lung biopsies from CVID patients usually show some degree of fibrosis, which can be extensive, and is the predominant finding in up to $6.5 \%$ of cases [64]. The presence of extensive lung fibrosis is associated with a poor prognosis [68].

In our study, we found two patients with radiological, BAL fluid cytology, and histological lung findings suggestive of ILD, and one patient with clinical and radiological findings commonly associated with severe interstitial lung fibrosis, which caused her death. 
Although not confirmed by biopsy, in four patients, the CT scan showed ground-glass opacities, pulmonary nodules, and mediastinal lymphadenopathy, which are images considered highly suggestive of ILD [64]. Taken together, our observations suggest adding SIgED to the immunodeficiencies potentially associated with ILD.

A substantial number of CVID patients (27\%, 95\% CI 22-32\%) develop autoimmune manifestations [29]. Studies have shown that SIgGD [9,12] SIgMD [13,45,69], IgGSD [56], and SIgAD [11,12,44,55] are also associated with systemic and organ-specific autoimmune diseases. The clinical spectrum of autoimmunity in CVID and other selective immunodeficiencies is very wide and includes a plethora of hematologic (cytopenia, thrombocytopenic purpura, hemolytic anemia, Evans syndrome), and non-hematologic diseases (autoimmune thyroid diseases, rheumatoid arthritis, unspecific inflammatory arthritis, Sjögren's syndrome, systemic lupus erythematous (SLE), autoimmune hepatitis) [65]. In our study, we found that SIgED was associated with hematologic and non-hematologic autoimmune diseases, with percentages similar to those described in other immunodeficiencies. Isolated and mixed autoimmune diseases were also significantly more frequent in adults and children with SIgED compared with control populations in previous studies $[23,25]$. As in our study, thyroid diseases (Hashimoto's thyroiditis and Grave's disease), cytopenias, SLE, and arthritis were autoimmune diseases reported in patients with SIgED [23,25]. Taken together, these findings support that autoimmunity is a relevant component of the clinical presentation of SIgED.

$\mathrm{CSU}$, in some cases associated with angioedema, was frequently diagnosed in our patients. In contrast, CSU and angioedema are not usually listed among the more common clinical manifestations in CVID $[29,65]$. However, some reports point out that we should not overlook the association of CSU with CVID [70-73]. CSU has been found in $4.9 \%$ of patients with SIgAD compared with $0.9 \%$ in controls [74], and in up to $12 \%$ of patients with SIgMD [75]. A statistically significant prevalence of CSU was observed in patients with SIgED (19\%) compared with controls $(0.8 \%)$ in one study [25], while another study did not find any differences between patients (11\%) and controls (11\%) [23].

Eczematous dermatitis was also found in a high percentage of our patients. The "eczema group" is frequently (33.7\%) diagnosed in patients with various primary immunodeficiencies [76], but it is not included among the most common manifestations of patients with CVID [29,64]. Interestingly, severe eczematous dermatitis is characteristic of diseases of the immune system associated with both autosomal dominant and autosomal recessive forms of hyper IgE syndrome [77]. In some of our patients, eczematous dermatitis was associated with severe itching requiring regular treatment with oral corticosteroids, in some cases complemented with immunosuppressive therapy. A previous study in patients with SIgED could not find any differences in skin rash complaints between patients and controls [23], while in another study, rashes diagnosed as psoriasis and seborrheic dermatitis were found to be significantly higher in SIgED patients than in controls [25].

Gastrointestinal symptoms that may mimic inflammatory bowel disease are very frequent in patients with CVID. Intermittent or persistent diarrhea (27\%, 95\% CI 21-34) [29,78], bloating (34\%) [78], and abdominal pain (26\%) [78], are the most common gastrointestinal symptoms. The enteropathy of CVID may affect any part of the gastrointestinal tract and is associated with various histological findings, including intraepithelial lymphocytosis $(46 \%)$, a decreased number of plasma cells in the GI tract mucosa $(62 \%)$, and lymphoid hyperplasia (38\%) [78]. Many other histological findings, such as eosinophilic or lymphocytic enteritis, villous atrophy, collagenous enteritis, and granulomatous inflammation are less frequently found in biopsies $[29,78]$. Studies in patients with SIgMD show great variability in the prevalence of gastrointestinal manifestations, without clearly differentiating those that may be due to an enteropathy similar to that found in CVID [14,44,55,75]. Both chronic and recurrent diarrhea are more common among individuals with SigAD than in the control population. However, many of these cases are associated with either celiac disease or inflammatory bowel disease [56]. A comparison study shows more biopsy-confirmed enteropathy cases among CVID patients (7\%) than among SigGD patients (3.2\%) [8]. Gas- 
trointestinal symptoms have not been reported associated with IgGSD [56]. Eleven (21\%) of our patients reported gastrointestinal symptoms suggestive of enteropathy. However, only five had been assessed by endoscopy $(9.6 \%)$, but all had histological findings (intraepithelial lymphocytosis, lymphoid hyperplasia, lymphocytic and eosinophilic enteritis) usually found in the enteropathy of CVID. Previous studies in SigED patients offer scant data on gastrointestinal symptoms, although they mention that some patients had been diagnosed with food allergy in some children [25], and inflammatory bowel disease and celiac disease in some adults [23], but without data from histological studies.

Liver diseases have been reported in up to $12.7 \%$ of CVID patients [67], ranging from elevated alkaline phosphatase to nodular regenerative hyperplasia (NRH), autoimmune hepatitis, liver cirrhosis, and primary sclerosing cholangitis (PSC) [79]. Some isolated cases of liver disease with NRH, and acute autoimmune hepatitis have been reported in patients with SIgAD [80] and SIgMD [81,82]. Acute severe autoimmune hepatitis (one patient) and PSC (two patients) progressing to cirrhosis were diagnosed in our SIgED patients. The three patients required liver transplantation. The two patients with PSC suffered from ulcerative colitis [83], and one of them developed a cholangiocarcinoma, which are both entities considered common complications in PSC [84].

Interestingly, high serum levels of $\operatorname{IgE}$ have been found associated with a lower incidence of biliary carcinoma in patients with PSC [85]. This is not an unexpected finding, since numerous epidemiological studies carried out in recent years have shown an inverse relationship between elevated IgE levels and malignant processes [28,86-89]. In keeping with these epidemiological observations, we found a strikingly high prevalence of malignancies $(30 \%)$, with non-Hodgkin lymphomas (13.4\%) topping the list in our patients. These findings are also very similar to those reported in some previous publications of SIgED patients, where a significant increase in malignant processes (lymphomas, lymphocytic leukemia, and epithelial cancers) was observed compared with the control group [25]. The high frequency of malignant processes in our study supports the relevant role played by IgE in antitumor surveillance detected in epidemiological studies.

The association between immunodeficiencies and cancer is well established. In CVID patients, the most commonly reported malignancies are non-Hodgkin lymphomas and various solid cancers (breast, colon, lung, gastric, ovarian, melanoma) [64,90,91]. A recent study has shown that the link between $\operatorname{IgE}$ and malignancies appears to be specific and independent of the presence of CVID in patients with IgE deficiency, which is a finding that lends further support to IgE's leading role in cancer development [92]. IgA deficiency is also associated with a moderately increased risk of cancer, with excess risks of gastrointestinal cancer not related to the presence of celiac disease [93]. Various types of cancer have been found in patients with SIgMD in some [44,69,94] but not all studies [94,95].

Fatigue as a major complaint was present in a high percentage (13.4\%) of our patients. Chronic fatigue was also found significantly more frequently in patients with SIgED than in controls in previous studies, $3.8 \%$ vs. $0.3 \%$ [25] and 30\% vs. $4 \%$ [23]. Fatigue is a very common complaint in patients with primary immunodeficiency disorders [96], particularly in patients with CVID (40\%) [29], but it has only been reported in isolated patients with other selective immunoglobulin deficiencies. The prevalence of polyarthralgias in our patients was high (17.3\%), but it was even less frequent than previously reported in patients with SIgED (32\% vs. $7 \%$ in controls) [23]. SIgED associated with both arterial hypertension $(37.7 \%)$ and ischemic heart disease $(25.2 \%)$ was previously reported by $\mathrm{E}$ Magen et al. [97]. We found a similar prevalence of arterial hypertension (33.3\%) but lower ischemic heart disease $(7.7 \%)$. The mechanisms involved in these associations remain to be elucidated [97]. The same group has also reported that in comparison to a control group, a significantly larger proportion of patients with SIgED presented with duodenal ulcers (DU) $(63.2 \%$ vs. $11.7 \%)$, who were positive for Helicobacter pylori (Hp) infection $(47.4 \%$ vs. $11.7 \%$ ) [98]. In our patients, the prevalence of DU was much lower (two patients, $3.8 \%$, both positive for HP), which concurs with previous studies [23], including one from the group of Magen et al. [25], which did not find that SIgED can predispose to DU. The reasons that 
could explain the striking difference between their own two studies $[25,98]$ are unclear and were not analyzed by the authors.

The number of patients in whom serum levels of IgG subclasses had been assessed was small and prevented us from evaluating the possible clinical impact when both deficiencies concur.

Currently, very little is known about the mechanisms responsible for the deficiency in $\mathrm{IgE}$, either in isolation or associated with deficiencies in other immunoglobulins. Similarly, the link between low IgE and the high risk of developing malignancy has yet to be elucidated. No abnormalities in the mechanisms involved in IgE synthesis have been reported so far in patients with SIgED. One study looked at the gene encoding activation-induced cytidine deaminase, which is an enzyme involved in immunoglobulin class switching, but the researchers could not find any mutation in patients with SIgED [99].

Our study has several limitations, such as the small number of patients recruited and its retrospective nature. We cannot exclude that some bias may have influenced our results. For example, the high prevalence of CSU and eczema found in our patients may be due to the fact that they are diseases treated by dermatologists and allergists who often include IgE measurement in their routine work-up. Moreover, we chose to use a stringent diagnostic criterion ( $\operatorname{IgE}<2.0 \mathrm{kU} / \mathrm{L})$ to increase the specificity in the diagnosis of SIgED. However, it remains unclear whether patients with $\operatorname{IgE}$ close to this level could also carry a similarly increased risk of developing diseases. There should be further studies gathering clinical data with different stratified IgE levels before a definitive serum IgE level can be established as a diagnostic threshold immunodeficient risk. Studies are also necessary to elucidate the clinical impact of complementary immunodeficient profiles such as associated IgG subtypes and the response to vaccines.

In summary, the data reported to date suggest that SIgED is characterized by a high prevalence of recurrent respiratory infections, asthma, autoimmune diseases, and malignancies [23-26]. Our study expands the spectrum of diseases associated with SIgED by adding bronchiectasis, enteropathy, CSU, eczematous dermatitis, LID, and liver diseases (PSC and hepatitis) to the known list. Although it is not clear why these diseases were not detected in previous studies, it is likely that the discrepancies are due to differences in the method used to recruit patients. In previous studies, patients were selected from allergy services [23,26] or with allergy-related symptoms [25], while in ours, patients were recruited without bias from the general hospital base, which could explain the higher prevalence of diseases that are not usually treated in the allergy units. Prospective studies based on broader populations are needed to further examine the role of SIgED in the development of different pathologies usually associated with immunodeficiencies. The possible genetic basis of SIgED is currently unknown and remains to be investigated. Hopefully, these studies will reveal whether SIgED can be added to the current list of antibody deficiencies.

Author Contributions: Conceptualization: C.P., A.V., and M.P. Methodology: C.P. and M.P. Validation: I.O.d.L., A.V., I.B., E.A., R.A., J.S., J.B., R.S., J.H.-R., J.-M.M., J.C. and E.C.V. Formal analysis: C.P. Data curation: I.B., E.A., R.A., J.S., J.B., R.S., J.H.-R., J.-M.M., J.C. and E.C.V. Writing-original draft: C.P. Review and editing: I.O.d.L., A.V., I.B., E.A., R.A., J.S., J.B., R.S., J.H.-R., J.-M.M., J.C., E.C.V. and M.P. All authors have read and agreed to the published version of the manuscript.

Funding: This research received no external funding.

Institutional Review Board Statement: The study was approved by the Ethics Committee of the Hospital Clinic (Ethical Code: HCB/2021/0758).

Informed Consent Statement: Patient consent was waived as only anonymized data obtained from routine clinical care was used.

Conflicts of Interest: The authors declare no conflict of interest. 


\section{References}

1. Bousfiha, A.; Jeddane, L.; Picard, C.; Al-Herz, W.; Ailal, F.; Chatila, T.; Cunningham-Rundles, C.; Etzioni, A.; Franco, J.; Holland, S.M.; et al. Human Inborn Errors of Immunity: 2019 Update of the IUIS Phenotypical Classification. J. Clin. Immunol. 2020, 40, 66-81. [CrossRef]

2. Tangye, S.G.; Al-Herz, W.; Bousfiha, A.; Chatila, T.; Cunningham-Rundles, C.; Etzioni, A.; Franco, J.L.; Holland, S.M.; Klein, C.; Morio, T.; et al. Human Inborn Errors of Immunity: 2019 Update on the Classification from the International Union of Immunological Societies Expert Committee. J. Clin. Immunol. 2020, 40, 24-64. [CrossRef]

3. Megha, K.B.; Mohanan, P.V. Role of immunoglobulin and antibodies in disease management. Int. J. Biol. Mcromol. 2021, 169, 28-38. [CrossRef]

4. Fitzsimmons, C.M.; Falcone, F.H.; Dunne, D.W. Helminth Allergens, Parasite-Specific IgE.; and Its Protective Role in Human Immunity. Front. Immunol. 2014, 5, 61. [CrossRef]

5. Plats-Mills, T.A.E.; Schuyler, A.J.; Erwin, E.A.; Commins, S.P.; Woodfolk, J.A. IgE in the diagnosis and treatment of allergic disease. J. Allergy Clin. Immunol. 2016, 137, 1662-1670. [CrossRef] [PubMed]

6. Ameratunga, R.; Allan, C.; Woon, S.T. Defining Common Variable Immunodeficiency Disorders in 2020. Immunol. Allergy Clin. N. Am. 2020, 40, 403-420. [CrossRef]

7. Chan, A.Y.; Torgerson, T.R. Primary immune regulatory disorders: A growing universe of immune dysregulation. Curr. Opin. Allergy Clin. Immunol. 2020, 20, 582-590. [CrossRef] [PubMed]

8. Filion, C.A.; Taylor-Black, S.; Maglione, P.J.; Radigan, L.; Cunningham-Rundles, C. Differentiation of Common Variable Immunodeficiency From IgG deficiency. J. Allergy Clin. Immunol. Pract. 2019, 7, 1277-1284. [CrossRef] [PubMed]

9. Barton, J.C.; Bertoli, L.F.; Barton, J.C. Comparisons of CVID and IgGSD: Referring physicians, autoimmune conditions, pneumovax reactivity, immunoglobulin levels, blood lymphocyte subsets, and HLA-A and -B typing in 432 adult index patients. J. Immunol. Res. 2014, 2014, 542706. [CrossRef]

10. Parker, A.R.; Skold, M.; Harding, S.; Barton, J.C.; Bertoli, L.F.; Barton, J.C. Pneumococcal vaccination responses in adults with subnormal IgG subclass concentrations. BMC Immunol. 2019, 20, 29. [CrossRef] [PubMed]

11. Swain, S.; Selmi, C.; Gershwin, M.E.; Teuber, S.S. The clinical implications of selective IgA deficiency. J. Transl. Autoimmun 2019, 2, 100025. [CrossRef]

12. Singh, K.; Chang, C.; Gershwin, M.E. IgA deficiency and autoimmunity. Autoimmun Rev. 2014, 13, 163-177. [CrossRef] [PubMed]

13. Campochiaro, C.; Atay, S.; Clark, K.E.N.; Ong, V.; Denton, C.P. Autoimmunity and immunodeficiency at the crossroad: Autoimmune disorders as the presenting feature of selective IgM deficiency. BMJ Case Rep. 2019, 3, e223180. [CrossRef] [PubMed]

14. Gupta, S.; Gupta, A. Selective IgM Deficiency-An Underestimated Primary Immunodeficiency. Front. Immunol. 2017, 8, 1056. [CrossRef] [PubMed]

15. Barton, J.C.; Barton, J.C.; Bertoli, L.F. Hypogammaglobulinemia E in 216 adults with IgG subclass deficiency and respiratory tract infections. Ann. Allergy Asthma Immunol. 2017, 119, 292-294. [CrossRef] [PubMed]

16. Gleich, G.J.; Averbeck, A.K.; Swedlund, H.A. Measurement of IgE in normal and allergic serum by radioimmunoassay. J. Lab. Clin. Med. 1971, 77, 690-698.

17. Polmar, S.H.; Waldmann, T.A.; Terry, W.D. IgE in immunodeficiency. Am. J. Pathol. 1972, 69, 499-512. [PubMed]

18. Stites, D.P.; Ishizaka, K.; Fudenberg, H.H. Serum IgE concentrations in hypogammaglobulinaemia and selective IgA deficiency. Studies on patients and family members. Clin. Exp. Immunol. 1972, 10, 391-397. [PubMed]

19. Elkuch, M.; Greiff, V.; Berger, C.T.; Bouchenaki, M.; Daikeler, T.; Bircher, A.; Navarini, A.; Heijnen, I.; Recher, M. Low immunoglobulin E flags two distinct types of immune dysregulation. Clin. Exp. Immunol. 2017, 187, 345-352. [CrossRef] [PubMed]

20. Unsworth, D.J.; Virgo, P.F.; Lock, R.J. Immunoglobulin E deficiency: A forgotten clue pointing to possible immunodeficiency? Annals Clin. Biochem. 2011, 48, 459-461. [CrossRef]

21. McVicker, S.; Karim, M.Y. IgE deficiency may indicate underlying hypogammaglobulinaemia? J. Clin. Pathol. 2014, 67, 832-833. [CrossRef]

22. Lawrence, M.G.; Palacios-Kibler, T.V.; Workman, L.J.; Schuyler, A.J.; Steinke, J.W.; Payne, S.; McGowan, E.C.; Patrie, J.; Fuleihan, R.L.; Sullivan, K.E.; et al. Low Serum IgE Is a Sensitive and Specific Marker for Common Variable immunodeficiency (CVID). J. Clin. Immunol. 2018, 38, 225-233. [CrossRef]

23. Smith, J.K.; Krishnaswamy, G.H.; Dykes, R.; Reynolds, S.; Berk, S.L. Clinical manifestations of IgE hypogammaglobulinemia. Ann. Allergy Asthma Immunol. 1997, 78, 313-318. [CrossRef]

24. Famuyiwa, F.; Rubinstein, I. Chronic sinopulmonary inflammatory diseases in adults with undetectable serum IgE in inner-city Chicago: A preliminary observation. Lung 2012, 190, 291-294. [CrossRef] [PubMed]

25. Magen, E.; Schlesinger, M.; David, M.; Ben-Zion, I.; Vardy, D. Selective IgE deficiency, immune dysregulation, and autoimmunity. Allergy Asthma Proc. 2014, 35, e27-e33. [CrossRef]

26. García Pavón Osorio, S.; Lopez Tiro, J.J.; Vera, J.G. IgE deficiency: A forgotten disease? Rev. Allerg. Mex. 2009, 56, $192-197$.

27. Hauck, F.; Gennery, A.R.; Seidel, M.G. Editorial: The Relationship Between Cancer Predisposition and Primary Immunodeficiency. Front. Immunol. 2019, 10, 1781. [CrossRef] [PubMed]

28. Ferastraoaru, D.; Bax, H.J.; Bergmann, C.; Capron, M.; Castells, M.; Dombrowicz, D.; Fiebiger, E.; Gould, H.J.; Hartmann, K.; Jappe, U.; et al. AllergoOncology: Ultra-low IgE.; a potential novel biomarker in cancer-a Position Paper of the European Academy of Allergy and Clinical Immunology (EAACI). Clin. Transl. Allergy 2020, 10, 32. [CrossRef] 
29. Janssen, L.M.A.; Van der Flier, M.; De Vries, E. Lessons Learned From the Clinical Presentation of Common Variable Immunodeficiency Disorders: A Systematic Review and Meta-Analysis. Front. Immunol. 2021, 12, 620709. [CrossRef]

30. Smith-Norowitz, T.A.; Kusonruksa, M.; Wong, D.; Norowitz, M.M.; Joks, R.; Durkin, H.G.; Bluth, M.H. Long-term persistence of IgE anti-influenza A HIN1 virus antibodies in serum of children and adults following influenza A vaccination with subsequent H1N1 infection: A case study. J. Inflamm. Res. 2012, 5, 111-116. [CrossRef]

31. Smith-Norowitz, T.A.; Mandal, M.; Joks, R.; Norowitz, L.T.; Weaver, D.; Durkin, H.G.; Bluth, M.H.; Kohlhoff, S. IgE anti-respiratory syncytial virus antibodies detected in serum of pediatric patients with Asthma. Hum. Immunol. 2015, 76, 519-524. [CrossRef] [PubMed]

32. Pellegrino, M.G.; Bluth, M.H.; Smith-Norowitz, T.; Fikrig, S.; Volsky, D.J.; Moallem, H.; Auci, D.L.; Nowakowski, M.; Durkin, H.G. HIV type 1-specific IgE in serum of long-term surviving children inhibits HIV type 1 production in vitro. AIDS Res. Hum. Retrovir. 2002, 18, 363-372. [CrossRef]

33. Smith-Norowitz, T.A.; Josekutty, J.; Silverberg, J.I.; Lev-Tov, H.; Norowitz, Y.M.; Kohlhoff, S.; Nowakowski, M.; Durkin, H.G.; Bluth, M.H. Long Term Persistence of IgE Anti-Varicella Zoster Virus in Pediatric and Adult Serum Post Chicken Pox Infection and after Vaccination with Varicella Virus Vaccine. Int. J. Biomed. Sci. 2009, 5, 353-358.

34. Smith-Norowitz, T.A.; Drew, H.; Norowitz, H.M.; Nowakowski, M.; Bluth, E.F.; Durkin, H.G.; Bluth, M.H. Detection of IgE anti-parvovirus antibodies in human breast milk. Ann. Clin. Lab. Sci. 2008, 38, 168-173. [PubMed]

35. Tam, J.S.; Jackson, W.T.; Hunter, D.; Proud, D.; Grayson, M.H. Rhinovirus specific IgE can be detected in human sera. J. Allergy Clin. Immunol. 2013, 132, 1241-1243. [CrossRef]

36. Secord, E.A.; Kleiner, G.I.; Auci, D.L.; Smith-Norowitz, T.; Chice, S.; Finkielstein, A.; Nowakowski, M.; Fikrig, S.; Durkin, H. IgE against HIV proteins in clinically healthy children with HIV disease. J. Allergy Clin. Immunol. 1996, 98, 979-984. [CrossRef]

37. Bluth, M.H.; Robin, J.; Ruditsky, M.; Norowitz, K.B.; Chice, S.; Pytlak, E.; Nowakowski, M.; Durkin, H.G.; Smith-Norowitz, T.A. IgE anti-Borrelia burgdorferi components (p18, p31, p34, p41, p45, p60) and increased blood CD8+CD60+ T cells in children with Lyme disease. Scand. J. Immunol. 2007, 65, 376-382. [CrossRef]

38. Starkl, P.; Watzenboeck, M.L.; Popov, L.M.; Zahalka, S.; Hladik, A.; Lakovits, K.; Radhouani, M.; Haschemi, A.; Marichal, T.; Reber, L.L.; et al. IgE Effector Mechanisms, in Concert with Mast Cells, Contribute to Acquired Host Defense against Staphylococcus aureus. Immunity 2020, 53, 1333. [CrossRef] [PubMed]

39. Szymanski, E.P.; Leung, J.M.; Fowler, C.J.; Haney, C.; Hsu, A.P.; Chen, F.; Duggal, P.; Oler, A.J.; McCormack, R.; Podack, E.; et al. Pulmonary nontuberculous Mycobacterial Infection. A Multisystem, Multigenic Disease. Am. J. Respir. Crit. Care Med. 2015, 192, 618-628. [CrossRef] [PubMed]

40. Becker, K.L.; Arts, P.; Jaeger, M.; Plantinga, T.S.; Gilissen, C.; Van Laarhoven, A.; Van Ingen, J.; Veltman, J.A.; Joosten, L.A.; Hoischen, A.; et al. MST1R mutation as a genetic cause of Lady Windermere syndrome. Eur. Respir. J. 2017, 49, 1601478. [CrossRef]

41. Ovrutsky, A.R.; Merkel, P.A.; Schonteich, E.; Bai, X.; Kinney, W.; Iseman, M.D.; Kart ija, M.; Knight, V.; Chan, E.D. Patients with non-tuberculous mycobacterial lung disease have elevated transforming growth factor-beta following ex vivo stimulation of blood with live Mycobacterium intracellulare. Scand. J. Infect. Dis. 2013, 45, 711-714. [CrossRef]

42. Greinert, U.; Schlaak, M.; Rüsch-Gerdes, S.; Flad, H.D.; Ernst, M. Low in vitro production of interferon-gamma and tumor necrosis factor-alpha in HIV-seronegative patients with pulmonary disease caused by nontuberculous mycobacteria. J. Clin. Immunol. 2000, 20, 445-452. [CrossRef] [PubMed]

43. Gupta, S.; Pattanaik, D.; Krishnaswamy, G. Common Variable Immune Deficiency and Associated Complications. Chest 2019, 156, 579-593. [CrossRef] [PubMed]

44. Aghamohammadi, A.; Cheraghi, T.; Gharagozlou, M.; Movahedi, M.; Rezaei, N.; Yeganeh, M.; Parvaneth, N.; Abolhassani, H.; Pourpak, Z.; Moin, M. IgA deficiency: Correlation between clinical and immunological phenotypes. J. Clin. Immunol. 2009, 29, 130-136. [CrossRef]

45. Lucuab-Fegurgur, D.L.; Gupta, S. Comprehensive clinical and immunological features of 62 adult patients with selective primary IgM deficiency. Am J Clin. Exp. Immunol. 2019, 8, 55-67.

46. Goldstein, M.F.; Hilditch, G.J.; Dvorin, D.J.; Belecanech, G.A. Immunoglobulin replacement for selective IgM immunodeficiency, bronchiectasis, and Asthma. Ann. Allergy Asthma Immunol. 2016, 116, 172-173. [CrossRef] [PubMed]

47. Mikhail, I.; Grayson, M.H. Asthma and viral infections: An intricate relationship. Ann. Allergy Asthma Immunol. 2019, 123, 352-358. [CrossRef]

48. De Valles-Ibáñez, G.; Esteve-Solé, A.; Piquer, M.; González-Navarro, E.A.; Hernandez-Rodriguez, J.; Laayouni, H.; GonzalezRoca, E.; Plaza-Martin, A.M.; Deyà-Martínez, A.; Martín-Nalda, A.; et al. Evaluating the Genetics of Common Variable Immunodeficiency: Monogenetic Model and Beyond. Front. Immunol. 2018, 9, 636. [CrossRef] [PubMed]

49. Janzi, M.; Melén, E.; Kull, I.; Wickman, M.; Hammarström, L. Rare mutations in TNFRSF13B increase the risk of asthma symptoms in Swedish children. Genes Immun. 2012, 13, 59-65. [CrossRef]

50. Eguiluz-Gracia, I.; Fernandez-Santamaria, R.; Testera-Montes, A.; Ariza, A.; Campo, P.; Prieto, A.; Perez-Sanchez, N.; Salas, M.; Mayorga, C.; Torres, M.J.; et al. Coexistence of nasal reactivity to allergens with and without IgE sensitization in patientswith allergic rhinitis. Allergy 2020, 75, 1689-1698. [CrossRef] 
51. Campo, P.; Eguiluz-Gracia, I.; Plaza-Serón, M.C.; Salas, M.; José Rodríguez, M.; Pérez-Sánchez, N.; González, M.; Molina, A.; Mayorga, C.; Torres, M.J.; et al. Bronchial asthma triggered by house dust mites in patients with local allergic rhinitis. Allergy 2019, 74, 1502-1510. [CrossRef]

52. Eckl-Dorna, J.; Villazala-Merino, S.; Campion, N.J.; Byazrova, M.; Filatov, A.; Kudlay, D.; Karsonova, A.; Riabova, K.; Khaitov, M.; Karaulov, A.; et al. Tracing IgE-Producing Cells in Allergic Patients. Cells 2019, 8, 994. [CrossRef]

53. Agondi, R.C.; Barros, M.T.; Kokron, C.M.; Cohon, A.; Oliveira, A.K.; Kalil, J.; Giavina-Bianchi, P. Can patients with common variable immunodeficiency have allergic rhinitis? Am. J. Rhinol. Allergy 2013, 27, 79-83. [CrossRef]

54. Edwards, E.; Razvi, S.; Cunningham-Rundles, C. IgA deficiency: Clinical correlates and responses to pneumococcal vaccine. Clin. Immunol. 2004, 111, 93-97. [CrossRef]

55. Jorgensen, G.H.; Gardulf, A.; Sigurdsson, M.I.; Sigurdardottir, S.T.; Thorsteinsdottir, I.; Gudmundsson, S.; Hammarström, L.; Ludviksson, B.R. Clinical symptoms in adults with selective IgA deficiency: A case-control study. J. Clin. Immunol. 2013, 33, 742-747. [CrossRef]

56. Khokar, A.; Gupta, S. Clinical and Immunological Features of 78 Adult Patients with Primary Selective IgG Subclass Deficiencies. Arch. Immunol. Ther. Exp. 2019, 67, 325-334. [CrossRef] [PubMed]

57. GEMA 4.4-Guía Española Para el Manejo del Asma. 2019. Available online: https://www.semg.es/index.php/consensosguias-y-protocolos/316-gema-4-4-guia-espa nola-para-el-manejo-del-asma (accessed on 1 May 2020).

58. Baumann, U.; Routes, J.M.; Soler-Palacín, P.; Jolles, S. The Lung in Primary Immunodeficiencies: New Concepts in Infection and Inflammation. Front. Immunol. 2018, 9, 1837. [CrossRef] [PubMed]

59. Rao, N.; Mackinnon, A.C.; Routes, J.M. Granulomatous and lymphocytic interstitial lung disease: A spectrum of pulmonary histopathologic lesions in common variable immunodeficiency-histologic and immunohistochemical analyses of 16 cases. Hum. Pathol. 2015, 46, 1306-1314. [CrossRef]

60. Tam, J.S.; Routes, J.M. Common variable immunodeficiency. Am. J. Rhinol. Allergy 2013, 27, 260-265. [CrossRef] [PubMed]

61. Kuehn, H.S.; Ouyang, W.; Lo, B.; Deenick, E.K.; Niemela, J.E.; Avery, D.T.; Schickel, J.-N.; Tran, D.Q.; Stoddard, J.; Zhang, Y.; et al. Immune dysregulation in human subjects with heterozygous germline mutations in CTLA4. Science 2014, 345, 1623-1627. [CrossRef] [PubMed]

62. Lopez-Herrera, G.; Tampella, G.; Pan-Hammarstrom, Q.; Herholz, P.; Trujillo- Vargas, C.M.; Phadwal, K.; Simon, A.K.; Moutschen, M.; Etzioni, A.; Mory, A.; et al. Deleterious mutations in LRBA are associated with a syndrome of immune deficiency and autoimmunity. Am. J. Hum. Genet. 2012, 90, 986-1001. [CrossRef]

63. Buchbinder, D.; Baker, R.; Lee, Y.N.; Ravell, J.; Zhang, Y.; McElwee, J.; Nugent, D.; Coonrod, E.M.; Durtschi, J.D.; Augustine, N.H.; et al. Identification of patients with RAG mutations previously diagnosed with common variable immunodeficiency disorders. $J$. Clin. Immunol. 2015, 35, 119-124. [CrossRef] [PubMed]

64. Ho, H.E.; Cunningham-Rundles, C. Non-infectious Complications of Common Variable Immunodeficiency: Updated Clinical Spectrum, Sequelae, and Insights to Pathogenesis. Front. Immunol. 2020, 11, 149. [CrossRef] [PubMed]

65. Schussler, E.; Beasley, M.B.; Maglione, P.J. Lung Disease in Primary Antibody Deficiencies. J. Allergy Clin. Immunol. Pract. 2016, 4, 1039-1052. [CrossRef]

66. Larsen, B.T.; Smith, M.L.; Tazelaar, H.D.; Yi, E.S.; Ryu, J.H.; Churg, A. GLILD Revisited: Pulmonary Pathology of Common Variable and Selective IgA Immunodeficiency. Am. J. Surg. Pathol. 2020, 44, 1073-1081. [CrossRef]

67. Shin, J.J.; Liauw, D.; Siddiqui, S.; Lee, J.; Chung, E.J.; Steele, R.; Hsu, F.I.; Price, C.; Kang, I. Immunological and Clinical Phenotyping in Primary Antibody Deficiencies: A Growing Disease Spectrum. J. Clin. Immunol. 2020, 40, 592-601. [CrossRef] [PubMed]

68. Popa, V.; Colby, T.V.; Reich, S.B. Pulmonary interstitial disease in Ig deficiency. Chest 2002, 122, 1594-1603. [CrossRef]

69. Goldstein, M.F.; Goldstein, A.L.; Dunsky, E.H.; Dvorin, D.J.; Belecanech, G.A.; Shamir, K. Selective IgM immunodeficiency: Retrospective analysis of 36 adult patients with review of the literature. Ann. Allergy Asthma Immunol. 2006, 97, 717-730. [CrossRef]

70. Altschul, A.; Cunningham-Rundles, C. Chronic urticaria and angioedema as the first presentations of common variable immunodeficiency. J. Allergy Clin. Immunol. 2002, 110, 664-665. [CrossRef]

71. Smith, A.A.; Humphrey, J.; McAuley, J.B.; Tharp, M.D. Common variable immunodeficiency presenting as chronic urticaria. J. Am. Acad. Dermatol. 2008, 59, S40-S41. [CrossRef] [PubMed]

72. Comberiati, P.; Costagliola, G.; Carli, N.; Legitimo, A.; D’Elios, S.; Consolini, R.; Petroni, D.G. Refractory Chronic Spontaneous Urticaria Treated With Omalizumab in an Adolescent With Common Variable Immunodeficiency. Front. Immunol. 2019, 10, 1700. [CrossRef]

73. Villatoro Santos, C.; Yacoub, M. Chronic urticaria and common variable immunodeficiency (CVID): An association to remember. BMJ Case Rep. 2021, 14, e239733. [CrossRef]

74. Magen, E.; Masalha, A.; Waitman, D.A.; Kahan, N.; Viner, I.; Klassov, L.; Vardy, D. Prevalence of dermatologic diseases among patients with selective immunoglobulin A deficiency. Allergy Asthma Proc. 2017, 38, 70-77. [CrossRef] [PubMed]

75. Chovancova, Z.; Kralickova, P.; Pejchalova, A.; Bloomfield, M.; Pechvatalova, J.; Vlkova, M.; PNechvatalova, J.; Vlkova, M.; Lizman, J. Selective IgM Deficiency: Clinical and Laboratory Features of 17 Patients and a Review of the Literature. J. Clin. Immunol. 2017, 37, 559-574. [CrossRef] 
76. Mauracher, A.A.; Gujer, E.; Bachmann, L.M.; Güsewell, S.; Pachlopnik Schmid, J. Patterns of Immune dysregulation in Primary Immunodeficiencies: A Systematic Review. J. Allergy Clin. Immunol. Pract. 2021, 9, 792-802.e10. [CrossRef]

77. Bergerson, J.R.E.; Freeman, A.F. An Update on Syndromes with a Hyper-IgE Phenotype. Immunol. Allergy Clin. North Am. 2019, 39, 49-61. [CrossRef]

78. Jørgensen, S.F.; Reims, H.M.; Frydenlund, D.; Holm, K.; Paulsen, V.; Michelsen, A.E.; Jørgensen, K.K.; Osnes, L.T.; Bratlie, J.; Eide, T.J.; et al. A Cross-Sectional Study of the Prevalence of Gastrointestinal Symptoms and Pathology in Patients with Common Variable Immunodeficiency. Am. J. Gastroenterol. 2016, 111, 1467-1475. [CrossRef] [PubMed]

79. Song, J.; Lleo, A.; Yang, G.X.; Zhang, W.; Bowlus, C.L.; Gershwin, M.E.; Lung, P.S.C. Common Variable Immunodeficiency and Liver Involvement. Clin. Rev. Allergy Immunol. 2018, 55, 340-351. [CrossRef] [PubMed]

80. Li, Y.; Xu, C.; Lin, N.; Zhao, Y.; Song, J. Nodular regenerative hyperplasia and portal hypertension are the characteristics of liver abnormalities in patients with selective immunoglobulin A deficiency. Clin. Res. Hepatol. Gastroenterol. 2020, 44, e123-e125. [CrossRef] [PubMed]

81. Sano, A.; Inoue, J.; Kakazu, E.; Ninomiya, M.; Iwata, T.; Morosawa, T.; Takai, S.; Nakamura, T.; Masamun, A. Acute-onset Autoimmune Hepatitis in a Patient with Selective Immunoglobulin M Deficiency. Intern. Med. 2019, 1, 2185-2190. [CrossRef]

82. Arahata, M.; Tajiri, K.; Nomoto, K.; Tsuneyama, K.; Minami, S.; Shimizu, Y. A novel type of selective immunoglobulin m deficiency in a patient with autoimmune liver cirrhosis with recurrent hepatocellular carcinoma: A case report and review of the literature. Int. Arch. Allergy Immunol. 2013, 161, 91-96. [CrossRef]

83. Dyson, J.K.; Beuers, U.; Jones, D.E.J.; Lohse, A.W.; Hudson, M. Primary sclerosing cholangitis. Lancet 2018, 391, 2547-2559. [CrossRef]

84. Song, J.; Li, Y.; Bowlus, C.L.; Yang, G.; Leung, P.S.C.; Gershwin, M.E. Cholangiocarcinoma in Patients with Primary Sclerosing Cholangitis (PSC): A Comprehensive Review. Clin. Rev. Allergy Immunol. 2020, 58, 134-149. [CrossRef] [PubMed]

85. Hirano, K.; Tada, M.; Mizuno, S.; Isayama, H.; Takahara, N.; Nagano, R.; Hamada, T.; Miyabayashi, K.; Ito, Y.; Mohri, D. Lower incidence of biliary carcinoma in patients with primary sclerosing cholangitis and high serum levels of immunoglobulin E. Clin. Gastroenterol. Hepatol. 2012, 10, 79-83. [CrossRef]

86. Ferastraoaru, D.; Rosenstreich, D. IgE deficiency and prior diagnosis of malignancy: Results of the 2005-2006 National Health and Nutrition Examination Survey. Ann. Allergy Asthma Immunol. 2018, 121, 613-618. [CrossRef]

87. Ferastraoaru, D.; Goodman, B.; Rosenstreich, D. Higher rates of malignancy in patients with immunoglobulin E deficiency and negative immediate hypersensitivity skin tests. Ann. Allergy Asthma Immunol. 2021, 126, 194-195. [CrossRef]

88. Ferastraoaru, D.; Schwartz, D.; Rosenstreich, D. Increased Malignancy Rate in Children With IgE Deficiency: A Single-center Experience. J. Pediatr. Hematol. Oncol. 2021, 43, e472-e477. [CrossRef] [PubMed]

89. Nieters, A.; Łuczyńska, A.; Becker, S.; Becker, N.; Vermeulen, R.; Overvad, K.; Aleksandrova, K.; Boeing, H.; Lagiou, P.; Trichopoulos, D.; et al. Prediagnostic immunoglobulin E levels and risk of chronic lymphocytic leukemia, other lymphomas and multiple myeloma-results of the European Prospective Investigation into Cancer and Nutrition. Carcinogenesis 2014, 35, 2716-2722. [CrossRef] [PubMed]

90. Resnick, E.S.; Moshier, E.L.; Godbold, J.H.; Cunningham-Rundles, C. Morbidity and mortality in common variable immune deficiency over 4 decades. Blood 2012, 119, 1650-1657. [CrossRef]

91. Cunningham-Rundles, C.; Lieberman, P.; Hellman, G.; Chaganti, R.S. Non-Hodgkin lymphoma in common variable immunodeficiency. Am. J. Hematol. 1991, 37, 69-74. [CrossRef]

92. Ferastraoaru, D.; Gross, R.; Rosenstreich, D. Increased malignancy incidence in IgE deficient patients not due to concomitant Common Variable Immunodeficiency. Ann. Allergy Asthma Immunol. 2017, 119, 267-273. [CrossRef] [PubMed]

93. Ludvigsson, J.F.; Neovius, M.; Ye, W.; Hammarström, L. IgA deficiency and risk of cancer: A population-based matched cohort study. J. Clin. Immunol. 2015, 35, 182-188. [CrossRef]

94. Caka, C.; Cimen, O.; Kahyaoğlu, P.; Tezcan, İ.; Cagdas, D. Selective IgM deficiency: Follow-up and outcome. Pediatr. Allergy Immunol. 2021, 32, 1327-1334. [CrossRef] [PubMed]

95. Ni, J.; Zhang, J.; Chen, Q.; Chen, Y.; Liu, J. The epidemiology and clinical features of selective immunoglobulin M deficiency: A single-center study in China. J. Clin. Lab. Anal. 2020, 34, e23289. [CrossRef] [PubMed]

96. Hajjar, J.; Guffey, D.; Minard, C.G.; Orange, J.S. Increased incidence of fatigue in patients with primary immunodeficiency disorders: Prevalence and associations within the US immunodeficiency network registry. J. Clin. Immunol. 2017, 37, 153-165. [CrossRef]

97. Magen, E.; Mishal, J.; Vardy, D. Selective IgE deficiency and cardiovascular diseases. Allergy Asthma Proc. 2015, 36, 225-229. [CrossRef]

98. Magen, E.; Waitman, D.A.; Goldstein, N.; Schlesinger, M.; Dickstein, Y.; Kahan, N.R. Helicobacter pylori infection in patients with selective immunoglobulin a deficiency. Clin. Exp. Immunol. 2016, 184, 332-337. [CrossRef]

99. Roa, S.; Isidoro-Garcia, M.; Davila, I.; Laffond, E.; Lorente, F.; Gonzalez-Sarmiento, R. Molecular analysis of activation-induced cytidine deaminase gene in immunoglobulin-E deficient patients. Clin. Dev. Immunol. 2008, 2008, 146715. [CrossRef] 